\title{
Maternal near miss: an Indian tertiary care centre audit
}

\author{
Padmaja Y. Samant, Juhi Dhanawat*
}

Department of Obstetrics and Gynecology, Seth GS Medical college and KEM Hospital, Parel, Mumbai, Maharashtra, India

Received: 28 January 2019

Accepted: 05 March 2019

*Correspondence:

Dr. Juhi Dhanawat,

E-mail: juhidhanawat@gmail.com

Copyright: () the author(s), publisher and licensee Medip Academy. This is an open-access article distributed under the terms of the Creative Commons Attribution Non-Commercial License, which permits unrestricted non-commercial use, distribution, and reproduction in any medium, provided the original work is properly cited.

\begin{abstract}
Background: In practical terms, women are considered near-miss cases when they survive conditions which threaten their life i.e. organ dysfunction. Despite advances in medical science and increased awareness of measures for safe childbirth, unacceptably high maternal morbidity and mortality continues to plague developing countries like India. Our's being a tertiary care centre, draws a lot number of high-risk patients and referrals. By auditing these near miss cases, we aim to identify the causes, factors leading to near miss, to identify management gaps to prevent near misses and maternal death.

Methods: Retro-prospective cross-sectional study done over one and a half year. Patients were included based on the inclusion criteria. A questionnaire was used to evaluate the prospective cases and the indoor case sheets were used for retrospective cases. After data entry in excel sheet, data analysis was done using SPSS 21. Results were tabulated.

Results: High number of Near Miss cases with preeclampsia being the commonest. Lack of proper facilities at the periphery health centers was the most common cause for referrals. Level 1 and level 2 delays were found in most cases.

Conclusions: Timely referral, with adequate treatment at the peripheral hospitals will majorly reduce Near miss. Hence, proper development and functioning of peripheral hospitals are needed.
\end{abstract}

Keywords: Audit, Maternal near-miss, Preeclampsia, Severe acute maternal morbidity

\section{INTRODUCTION}

Maternal near miss is defined as a woman who otherwise would have died due to a complication that occurred during pregnancy, childbirth or within 42 days of termination of pregnancy, but survived. The prevalence of maternal near miss varies among different countries based on availability and quality of health care. In a systematic review using disease specific criteria, near miss rates are reported to be between $0.6 \%$ and $14.98 \%$. $^{1}$ Mumbai being India's one of the leading cities in providing good health care, with four tertiary hospitals, multiple private hospitals, and peripheral hospitals, still has an alarming rate of maternal mortality and morbidity, despite continuous efforts to reduce it. It is difficult to reflect pregnant women's health status by only mortality indicators; hence Severe Acute Maternal Morbidity (SAMM) is used. SAMM is superior to mortality indicators in giving attention to surviving women's reproductive health and lives, and can be used in developed as well as developing countries. In 2009 WHO set up clinical, laboratory and management criteria for the identification of these cases.

The place of study is a metropolitan tertiary care center and also drains nearby areas. Because of delay in referral, resource constraints like non-availability of blood and blood products, rapidly developing antibiotic resistant 
bacterial strains; cases become critical. Traffic congestion, unorganised referral systems cause delay in transfer. ${ }^{2,3}$ Low risk cases that should otherwise be managed by peripheral hospitals are primarily registered in tertiary set ups and consume resources and are also responsible for nosocomial infection. Unfavourable ratio of nursing and other staff to patients causes increases the burden on the existing staff. ${ }^{4}$

This paper analyses the near misses from the above points of view and suggests recommendations and strategies to reduce the morbidity of mothers.

\section{METHODS}

It was a retro-prospective study at a metropolitan tertiary care centre, which included women according to the WHO near miss inclusion criteria over 20 months. Institutional ethics committee approval was taken. All details were recorded by studying the case sheets of the patients. Gaps in diagnosis and treatment of near miss cases were identified. Prospective study was done by means of personal interview and asking relevant questions to the patients themselves or their relatives in case of very sick women. The questions focused on the patients' condition at the time when they were referred to the hospital e.g. their symptoms, treatment given, causes of referral. This helped to identify system gaps.

The number of maternal deaths during the same period was noted. Comparing the maternal deaths with near-miss would give the ratio of deaths to near miss indicating the efficiency of health system.

\section{Inclusion criteria}

Women who were pregnant/ in labor/ delivered/ aborted; up to 42 days from termination of pregnancy, admitted in Obstetric department with any of the listed conditions or those who developed any of these conditions during their indoor stay.

\section{Conditions}

- Severe Post-partum hemorrhage,

- Eclampsia,

- Severe sepsis (with multi organ dysfunction),

- Rupture of uterus,

- Admission to the intensive care unit,

- Cardiovascular dysfunction like shock,

- Use of vasoactive drugs,

- Cardiopulmonary resuscitation,

- $\quad$ Severe hypotension/ acidosis ( $\mathrm{pH}<7.1$ ),

- Respiratory dysfunction like acute cyanosis, acute respiratory distress syndrome,

- Acute renal failure, oliguria not responding to fluids or diuretics,

- Massive blood transfusion (>5unit),
- Severe acute thrombocytopenia (platelets $<50,000 / \mathrm{ml})$,

- Hepatic dysfunction like jaundice in the presence of pre-eclampsia, bilirubin $>6 \mathrm{mg} / \mathrm{dl}$,

- Uterine infection or infection leading to hysterectomy,

- Neurological dysfunction like coma, stroke, status epilepticus, total paralysis.

\section{Exclusion criteria}

- Women that developed the above conditions unrelated to pregnancy,

- Those not willing to participate in the study,

- Unconscious patients whose relatives do not wish to participate in the study.

As per WHO recommendations, severe maternal outcomes (deaths plus near misses) divided by number of women giving birth within a given time period was considered for sample size calculation.

On an average, no. of maternal deaths plus no. of nearmiss cases in OBGYN department is 900 (calculated from annual data compiled in the year 2013) and total no. of women giving birth is on average 8000 per year, therefore prevalence is $11 \%$. Sample size calculated by this method is very less; hence, convenience sampling method was applied. Total number of cases taken were 600,500 retrospective and 100 prospective.

\section{Statistical analysis}

After data collection, data entry was done in Excel. Data analysis was done with the help of SPSS Software version 21. Quantitative data like duration of Hospital stay and age is presented with the help of Mean, Standard Deviation, Median and IQR. Qualitative data like Gravida Para Status and symptoms treatment given, level of delay, referral causes etc are presented with the help of Frequency and Percentage table and presented with pie chart and bar diagrams.

\section{RESULTS}

There from April 2016 to May 2017, author had a total of 600 near miss cases, with 42 maternal deaths in the same time period and total live births of 5330. The near miss ratio per 1000 live birth was 112.57. The proportion between maternal near miss cases and maternal death was 14.28 .

Being a tertiary care centre very high risk cases primarily register in the set up under study. 21-30 years corresponds to the most susceptible age group for pregnancy, hence this explains why most near miss cases fall into this age group. Mean age was $26.96 \pm 4.7$ years. Most were primiparas (Table 1). 
Table 1: Distribution of antenatal registrations, and parity status.

\begin{tabular}{|lll|}
\hline Antenatal care status & Frequency & Percentage \\
\hline Unregistered & 33 & $6 \%$ \\
\hline Registered* & 315 & $53 \%$ \\
\hline $\begin{array}{l}\text { Transferred (but } \\
\text { registered elsewhere) }\end{array}$ & 252 & $42 \%$ \\
\hline Parity & & \\
\hline Primipara & 364 & $61 \%$ \\
\hline Multipara & 196 & $33 \%$ \\
\hline Total & 560 & $93 \%$ \\
\hline Age groups & & \\
\hline$<20$ years & 32 & $5 \%$ \\
\hline $21-30$ years & 446 & $74 \%$ \\
\hline $31-40$ years & 118 & $20 \%$ \\
\hline$>40$ years & 4 & $1 \%$ \\
\hline
\end{tabular}

Most common cause of maternal near miss was severe preeclampsia, with $10 \%$ being eclampsia. Severe postpartum hemorrhage was in $10 \%$, sepsis in $7 \%$ and ruptured uterus in $3 \%$. Commonest organs that were affected heart and liver (Table 2).

Table 2: Causes of maternal near miss and organ dysfunctions.

\begin{tabular}{|lll|}
\hline Obstetric complication & Frequency & Percentage \\
\hline Severe PPH & 59 & $10 \%$ \\
\hline $\begin{array}{l}\text { Severe preeclampsia } \\
\text { (including HELLP) }\end{array}$ & 306 & $51 \%$ \\
\hline Eclampsia & 57 & $10 \%$ \\
\hline Sepsis & 41 & $7 \%$ \\
\hline Ruptured uterus & 19 & $3 \%$ \\
\hline $\begin{array}{l}\text { Critical Organ dysfunction/ life threatening } \\
\text { conditions }\end{array}$ & 91 & $15 \%$ \\
\hline CVS dysfunction & 36 & $6 \%$ \\
\hline Respiratory dysfunction & 54 & $9 \%$ \\
\hline Renal dysfunction & 46 & $8 \%$ \\
\hline $\begin{array}{l}\text { Coagulation/hematologic } \\
\text { dysfunction }\end{array}$ & 85 & $14 \%$ \\
\hline Hepatic dysfunction & 41 & $7 \%$ \\
\hline Neurologic dysfunction & 15 & $3 \%$ \\
\hline $\begin{array}{l}\text { Uterine dysfunction/ } \\
\text { hysterectomy }\end{array}$ & & \\
\hline
\end{tabular}

There were $31.5 \%$ required blood and blood product transfusion, with $25 \%$ being admitted in the intensive care unit. Most peripheral hospitals do not have blood banks and intensive care units making these the most common causes for referrals (Table 3 ).

Most common cause of delay was at level 1 where patients themselves did not reach the health care set up in time; or first point of care was deficient. Level 2 delay was $11 \%$ where in patients initially went to a public health centre or to a private physician close to their home. They were treated with anti-hypertensive and Magnesium sulfate, a few were investigated for their initial complaint, some were given steroids for fetal lung maturation, and some others were not treated $(49 \%)$, and were directly transferred to the tertiary health centre. This delay comprised of the majority reflecting inadequacy of peripheral hospitals (Table 4).

Table 3: Distribution of Critical interventions or intensive care unit admission.

\begin{tabular}{|lll|}
\hline & Frequency & Percentage \\
\hline Use of blood products & 189 & $31.5 \%$ \\
\hline Interventional radiology & 2 & $0.3 \%$ \\
\hline Laparotomy & 14 & $2.3 \%$ \\
\hline ICU admission & 150 & $25 \%$ \\
\hline
\end{tabular}

Table 4: Distribution of Cause of referral.

\begin{tabular}{|lll|}
\hline Non availability of doctor & 13 & $2.1 \%$ \\
\hline Non availability of OT & 23 & $3.8 \%$ \\
\hline $\begin{array}{l}\text { Non availability of blood } \\
\text { products }\end{array}$ & 72 & $12 \%$ \\
\hline Non availability of NICU & 66 & $11 \%$ \\
\hline $\begin{array}{l}\text { Non Availability of } \\
\text { essential facilities (HDU, } \\
\text { equipment, super } \\
\text { speciality) }\end{array}$ & 218 & $36.33 \%$ \\
\hline Level of delay & 116 & $19 \%$ \\
\hline Level 1 & 63 & $11 \%$ \\
\hline Level 2 & 6 & $1 \%$ \\
\hline Level 3 & & \\
\hline
\end{tabular}

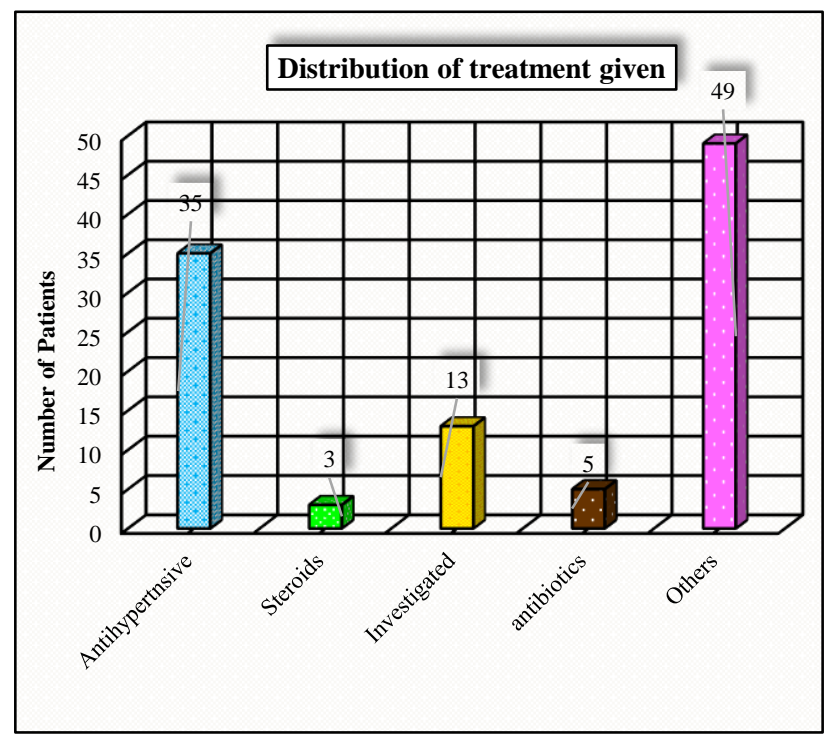

Figure 1: Percentage of initial treatment given at the periphery.

\section{DISCUSSION}

Maternal mortality is the tip of the iceberg and there is a large base of the severe acute maternal morbidity, which 
is frequently ignored. By auditing maternal morbidity, we can identify and fill the gaps of the health system. Traditionally, maternal deaths were being evaluated as a key to maternal death prevention, but this approach failed to provide complete information. Hence, now we audit maternal near misses to look into the whole picture regarding obstetrical care, its outcome, morbidity and mortality status of the mother, resources available, level of delay and most importantly, root cause of a maternal near miss. A near miss case if not treated appropriately and within the right time, can result in death. Therefore, identifying causes and circumstances leading to it is very important. Analysis of maternal near misses provides insights to better preventive planning. Since the mother survives, valuable details on her experience can be got. Maternal near miss is just one step away from maternal death, any information about the event will prove beneficial in preventing maternal death. ${ }^{5}$ If both maternal near misses and maternal death are audited at the same time, maternal near misses can act as controls. According to the World Health statistics 2011, deliveries attended by skilled health personnel rose from $58 \%$ in 1990 to $68 \%$ in 2008. In India, The Janani Suraksha Yojana (JSY) scheme, cash incentive scheme, has been initiated to promote institutional delivery. The increase in load on the health facilities may compromise the quality of care, and hence financial resources and health care personnel should be increased proportionately. A study on the impact of JSY scheme has shown increase in institutional deliveries of maternal near misses but no decline in maternal deaths. ${ }^{6}$

Near miss incidence in our study is 112.57 per 1000 live births (a statistical artifact as cases in the municipal ward or district are not taken as denominator). Our booked patients consist of a large number of high risk patients, who are potential near misses. Maternal near miss ratio is 17.8 per 1000 in Manipal, 25.2 per 1000 in south east Iran, 44.3 per 1000 in Brazil, 3.83 per 1000 in Scotland, and 34 per 1000 in WHO survey.,7-10 There a wide variability on prevalence of maternal near miss in different parts of the world depending on the socioeconomic conditions of the area, the availability of health resources, the education of the people.

The near miss to mortality ratio, was $14.2: 1$ in this study, which means that for every 14-15 maternal near miss, there was 1 maternal death. Higher the ratio, better the health care. Syrian study had a ratio of $60: 1$, with a study in Nepal having a ratio of 7.2:1. ${ }^{11,12}$ This ratio is also seen in African countries where it ranges from 5-12:1.13 European countries have ratios of 117-223:1, indicating a far better health care. ${ }^{14}$

In our study $61 \%$ of the maternal near miss was primiparas, while $33 \%$ were multiparas (Table 1). It is similar to all other studies conducted in various parts of India and the world. ${ }^{5,75-17}$ Our study had more incidence of pregnancy induced hypertension which may be due to more detection due to wider antenatal care coverage.
Most of the women fell into the age group between 2130years (74\%), corresponding to the most susceptible age group for pregnancy, hence this explains why most near miss cases fall into this age group (Table 1). This is similar to study conducted by Purandare et al. ${ }^{18}$ Mean age of near miss patients was $24 \pm 3$ years, in Western Rajasthan. ${ }^{16}$ Similar findings were present in a study done in Gwalior, Manipal and South East Iran. 5,7,19 On the contrary, study conducted in Pakistan, the mean age of maternal near miss was $28 \pm 5$ years. ${ }^{20}$ In a study in Assam, mean age of maternal near miss was 15-20 years, indicating early marriage and pregnancy, poverty and lack of education. ${ }^{16}$

In our tertiary care centre, a large number of high risk cases are registered for antenatal care (53\%).

\section{This indicates}

- Unmet need for well equipped referral care centers,

- Need for stronger linkage with peripheral centers via telemedicine which may enable expert opinion,

- Need for more incentives to doctors to practice in periphery.

In this study, $36.33 \%$ cases were referred due to non availability of essential facilities at the periphery hospitals, which mostly comprised of non-availability of critical care, lack of medications and lack of skills. 12\% were referred due to lack of blood and blood products, with $11 \%$ referred due to non- availability neonatal care services. $3.8 \%$ were referred due to non availability of operation theatre, and $2.1 \%$ referred due to non availability of doctor. These findings depict the lack of resources at the periphery hospitals (Table 4).

Level 1 delay was found in $19 \%$ of the cases. These comprised of lack of awareness of the patient or caregivers. $11 \%$ of the cases had Level 2 delay due to late referral, or improper diagnosis and management at the periphery hospitals, or lack of transport facility. $1 \%$ delay was found at the tertiary care hospital, which was mostly due to late diagnosis and inadequate management. Delay could have been possible due to hospital management, non-availability of support staff, or non availability of medicines, but these factors could not be evaluated in this study. Rest of the cases, there was no delay (Table 4). One study conducted by Purandare et al, in six medical colleges across India, delay in seeking help was seen in $60.6 \%$ of the cases, with other transport and logistical problems seen in $30.3 \%$. Lack of blood was seen in $7.6 \%$, with lack of health personnel and lack of skills seen in $16.7 \% .^{18}$ In developing countries, $75 \%$ of women are already in critical state when they reach the tertiary care centre, thereby underscoring the significance of the first two delays. ${ }^{15,21}$ Availability, accessibility of health care resources, cost of health care, education of the people, behavioral factors, awareness play an important role in the utilization of maternal health services. ${ }^{17,22-24}$ Access to good emergency obstetric care unit (EmOC) will play 
important role in improving maternal outcome. It is the term used to describe the essential elements of obstetric care for management of complications arising during pregnancy, delivery, and postpartum period. ${ }^{25}$ Tamil Nadu has been successful in declining maternal deaths due to series of initiatives such as skilled birth attendance for all births and making emergency obstetric care units available. $^{26}$

In the present study, it was found that most common cause of near miss is severe preeclampsia contributing to $51 \%$, while ecclampsia and severe postpartum hemorrhage being $10 \%$ each, followed by sepsis and ruptured uterus (Table 2). Most studies showed commonest cause to be haemorrhage. .,5,7,16,18 $^{\text {The cause }}$ of hemorrhage being second to hypertensive disorders in our study could be due to lack of documentation of post partum hemorrhage.

$15 \%$ cases had cardiovascular dysfunction, with $14 \%$ cases having hepatic dysfunction. Renal, respiratory, and neurological dysfunctions were seen in 9, 6 and $7 \%$ of the cases respectively. $8 \%$ cases had hematological problems, with $3 \%$ cases having uterine dysfunction (Table 2). Many patients had affectation of more than one organ systems. In contrast to our study, study conducted in Iran, $8.6 \%$ of the cases required ICU admission with $3.4 \%$ requiring blood transfusion. ${ }^{6}$ Organ system dysfunction was present in $78.8 \%$ of the near miss cases in a study conducted in Assam, with cardiovascular system, neurological system and uterine rupture being most commonly involved, which is similar to a study in Nigeria, and another study done by Gandhi et al. ${ }^{16,27,28}$ In a study conducted in Rwanda, 30\% cases had peritonitis, $3 \%$ cases had malaria, and $3.6 \%$ cases had cardiomyopathy. ${ }^{29}$ Our study did not have any case of peritonitis, malaria although we had one case of cardiomyopathy. We had multiple cases of hepatitis E, usually seen more in the monsoon months, leading to high incidence of hepatic dysfunction. Our area also sees a large number of Tuberculosis cases, which affect multiple organs, contributing to a significant number of maternal near- miss. In this study, death due to anesthetic cause has not been evaluated.

In this study, level 1 and level 2 delays were found to be very high, indicating that education of women, family support are important preventable factors of maternal near miss. Early recognition of the problem, in time referral, with good accessibility to transport, proper use of the health resources will play an important role in preventing maternal near miss. Our study had a high number of high risk registered cases; ensuring proper antenatal care of these patients with proper follow up of the patients in the outpatient department will significantly reduce near misses. Though the patients register at a tertiary care center, but due to long distance and difficulty in travelling, follow up is erratic, thereby resulting in late arrival at the hospital or with worsened medical condition. This leads to increased chances of mortality.
These women sometime follow up at a public hospital close to their residence, but these peripheral hospitals may have inadequate human resource due to which management may be compromised. Free medicinal supply is deficient, operation theatre and ICU facilities are often inadequate. Community education will improve women's reproductive health seeking, thereby reducing maternal near miss.

Peripheral hospitals see a large number of near miss cases, thus they should be well staffed, equipped with medications, well functioning operation theatre and blood bank.

Many peripheral hospitals in the city where the study has been conducted do not have medical and neonatal intensive care units. Many of our referrals are due to the above reason, thus increasing work load of a tertiary care hospital. This causes problems in resource allocation.

\section{CONCLUSION}

All causes of maternal near miss cannot be prevented, but certain causes like infrastructural deficiencies, nonavailability of health care providers can be rectified. Government along with the medical community have to work together to decrease the burden of Near miss. Mobile medical units should be made available to reach the periphery, rural patients should be encouraged to have regular antenatal visits so that hypertension, anemia, fetopelvic disproportion can be detected early. Telemedicine facilities should be made available for better treatment of patients. Public and private hospital partnership should be strengthened.

\section{ACKNOWLEDGMENTS}

Authors would like to thank the Dean of his institute for permission.

\section{Funding: No funding sources Conflict of interest: None declared \\ Ethical approval: The study was approved by the Institutional Ethics Committee}

\section{REFERENCES}

1. Tuncalp O, Hindin M, Souza J, Chou D, Say L. The prevalence of maternal near miss: a systematic review. British J Obstet Gynecol. 2012;119(6):63561.

2. Taly A, Gupta S, Jain N. Maternal intensive care and near miss mortality in obstetrics. J Obstet Gynecol Indsep. 2004;54:478-82.

3. Jayaratnam S, De costa C, Hernet P. Developing an assessment tool for maternal morbidity near miss- a prospective study in a large Australian regional hospital. Aus New Zealand J Obstet Gynecol. 2011;51:421-5. 
4. National Health Mission; Maternal near miss review operational guidelines; December 2014. Available at: www.nhm.gov.in.

5. Naderi T, Foroodnia S, Omidi S, Samadani F, Nakhaee N. Incidence and correlates of maternal near miss in southeast Iran. Int $\mathbf{J}$ Reprod Med. 2015;2015:914713.

6. Gupta SK, Pal DK, Tiwari R, Garg R, Shrivastava AK, Sarawagi R, et al. Impact of JananiSurakshaYojana on institutional delivery rate and maternal morbidity and mortality: an observational study in India. J Health Popul Nutr. 2012;30:464-1.

7. Roopa PS, Verma S, Rai L, Kumar P, Pai M, ShettyJ. Near miss obstetric events and maternal deaths in a tertiary care hospital: an audit. J Pregnancy. 2013.

8. Sousa M, Cecatti J, Hardy E, Serruya S. Severe maternal morbidity (near miss) as a sentinel event of maternal death. An attempt to use routine data for surveillance. Reproductive Health. 2008;5(1):article6.

9. Brace V, Penney G, Hall M. Quantifying severe maternal morbidity: a Scottish population study. BJOG. 2004;111(5):481-4.

10. Souze JP, Cecath JG, Faundes A, Morais SS, Villai J, Caroli $\mathrm{G}$, et al. Maternal near miss and maternal death in the World Health Organisation 2005 global survey on maternal and perinatal health. Bull World Heal Org. 2010;88:113-9.

11. Almerie Y, Almerie MQ, Matar HE, Shahrour Y, Al Chamat AA, Abdulsalam A. Obstetric near-miss and maternal mortality in maternity university hospital, Damascus, Syria: a retrospective study. BMC Pregnancy Childbirth. 2010;10(1):65.

12. Shrestha N, Saha R, Karki C. Near miss maternal morbidity and maternal mortality at Kathmandu Teaching Hospital, Kathmandu univ. Med J (KUMJ). 2010;8:222-6.

13. Prual A, Huguet D, Garbin O, Rabe G. Severe obstetric morbidity of the third trimester, delivery and early puerperium in Niamey (Niger). Afr J Reprod Health. 1998;2(1):10-9.

14. Roosmalen JV, Zwart J. Severe acute maternal morbidity in high-income countries. Best Practice and Research: Clin Obstet Gynecol. 2009;23(3):297304.

15. Mustafa R, Hashmi H. Near-miss obstetrical events and maternal death. J Coll Physcians Surg Pak. 2009;19(12):781-5.

16. Purandare C, Bhardwaj A, Malhotra M, Bhushan H, Chhabra S, Shivkumar P. Maternal near-miss reviews: lessons from a pilot programme in India. BJOG. 2014;121:105-11.

17. Sarma H, Kalita A. A prospective study of maternal near-miss and maternal mortality cases in FAAMCH,
Barpeta with special reference to its aetiology and management: First 4 months report. J Obs Gynaecol Barpeta. 2014;1(2).

18. Khan KS, Wojdyla D, Say L, Gülmezoglu AM, Van Look PF. WHO analysis of causes of maternal death: A systematic review. Lancet. 2006;367:1066-74.

19. Kalra P, Kachhwala C. Obstetric near miss morbidity and maternal mortality in a tertiary care centre in western Rajasthan. Ind J Pub Heal. 2014;58(3).

20. Bindal J, Solanki G. Clinical and etiological study of maternal near-miss at a tertiary referral hospital of Central India. Ind J Obstet Gynaecol Res. 2016;3(1):28-31.

21. Rööst M, Altamirano VC, Liljestrand J, Essén B. Priorities in emergency obstetric care in Bolivia Maternal mortality and near? miss morbidity in metropolitan La Paz. BJOG. 2009;116:1210-7.

22. Goffman D, Madden RC, Harrison EA, Merkatz IR, Chazotte C. Predictors of maternal mortality and near-miss maternal morbidity. J Perinatol. 2007;27:597-601.

23. Rööst M, Jonsson C, Liljestrand J, Essén B. Social differentiation and embodied dispositions: a qualitative study of maternal care seeking behaviour for near miss morbidity in Bolivia. Reprod Health. 2009;6:13.

24. Sunil TS, Rajaram S, Zottarelli LK. Do individual and program factors matter in the utilization of maternal care services in rural India? a theoretical approach. Soc Sci Med. 2006;62:1943-57.

25. Saving Mothers' Lives: what works. White Ribbon Alliance/India. 2002:99.

26. Vora KS, Mavalankar DV, Ramani KV, Upadhyaya M, Sharma B, Iyengar S, et al. Maternal health situation in India: A case study. J Health Popul Nutr. 2009;27:184-201.

27. Oladapo O, OSule A. "Near miss" obstetric events and maternal near deaths in Sagamu, Nigeria: a retrospective study. Reproductive Health. 2005;2:9.

28. Gandhi MN, Welz T, Ronsmans C. Severe acute maternal morbidity in rural South Africa. Int $\mathbf{J}$ Gynecol Obstet. 2004;87:180-7.

29. Rulisa S, Umuziranenge I, Small M, van Roosmalen J. Maternal near miss and mortality in a tertiary care hospital in Rwanda. BMC Pregnancy Childbirth. 2015;15(1):203.

Cite this article as: Samant PY, Dhanawat J. Maternal near miss: an Indian tertiary care centre audit. Int J Reprod Contracept Obstet Gynecol 2019;8:1874-9. 